RESEARCH REPORT

\title{
Work stress, smoking status, and smoking intensity: an observational study of 46190 employees
}

\author{
Anne Kouvonen, Mika Kivimäki, Marianna Virtanen, Jaana Pentti, Jussi Vahtera
}

J Epidemiol Community Health 2005;59:63-69. doi: 10.1136/jech.2004.019752

See end of article for authors' affiliations

.....................

Correspondence to: Dr A Kouvonen, Department of Psychology, POB 9, Fl-00014 University of Helsinki, Finland.; anne.kouvonen@ luukku.com

Accepted for publication 22 May 2004
Study objective: To examine the relation between work stress, as indicated by the job strain model, and the effort-reward imbalance model, and smoking.

Setting: Ten municipalities and 21 hospitals in Finland.

Design and participants: Binary logistic regression models for the prevalence of smoking were related to survey responses of 37309 female and 8881 male Finnish public sector employees aged 17-65. Separate multinomial logistic regression models were calculated for smoking intensity for 8130 smokers. In addition, binary logistic regression models for ex-smoking were fitted among 16277 former and current smokers. In all analyses, adjustments were made for age, basic education, occupational status, type of employment, and marital status.

Main results: Respondents with high effort-reward imbalance or lower rewards were more likely to be smokers. Among smokers, an increased likelihood of higher intensity of smoking was associated with higher job strain and higher effort-reward imbalance and their components such as low job control and low rewards. Smoking intensity was also higher in active jobs in women, in passive jobs, and among employees with low effort expenditure. Among former and current smokers, high job strain, high effortreward imbalance, and high job demands were associated with a higher likelihood of being a current smoker. Lower effort was associated with a higher likelihood of ex-smoking.

Conclusions: This evidence suggests an association between work stress and smoking and implies that smoking cessation programmes may benefit from taking into account the modification of stressful features of work environment.
W ork stress has repeatedly predicted increased health problems, in particular cardiovascular morbidity and mortality ${ }^{1-9}$ but this association may not exclusively reflect stress induced pathophysiological changes. ${ }^{10}$ It has been hypothesised that work stress may also indirectly affect health by increasing the likelihood of health risk behaviours such as smoking, a known risk factor $^{1-12}$ of coronary heart disease, cancer, emphysema, and osteoporosis among other things. However, evidence on the association between work stress and smoking has remained uncertain.

According to the job strain model, ${ }^{13-14}$ the dominant work stress theory, health risk arises from high job demands and low job control and their combination, referred to as job strain. Previous empirical research, which predominantly relates to male populations, ${ }^{15-19}$ has produced mixed results on the association between job strain components and smoking. There are several studies reporting the prevalence or intensity of smoking to be associated with high job demands, ${ }^{20-24}$ with low job control, ${ }^{151921}$ or with job strain. ${ }^{1623} 25$ However, many other studies have reported no association between smoking and job demands, , $^{18-19} 26$ job control, ${ }^{182427}$ or job strain. ${ }^{15} 182628-29$ Furthermore, in one study, ${ }^{20}$ low job control was associated with a smaller quantity of cigarettes smoked ${ }^{22}$ and high job strain with lower prevalence of smoking.

The effort-reward model, ${ }^{30}$ a more recent work stress theory, focuses on a negative trade off between experienced "costs" and "gains" at work. In this model, a high workload is hypothesised to be an important extrinsic factor contributing to high effort expenditure. Low rewards, the other component of imbalance, refer to shortage in terms of money, esteem, and occupational status control. High effort-reward imbalance has been associated with a greater likelihood of smoking $^{31}$ but the extent to which this association is independent of job strain is unknown.

To extend understanding of the relation between work stress and smoking, we examined whether work stress is associated with smoking status and smoking intensity in a large cohort of Finnish female and male employees. We tested whether the two alternative work stress models (the job strain model and the effort-reward imbalance model) independently link with smoking.

A recent survey reports that 19\% of Finnish women and $26 \%$ of men smoke daily. Among men, smoking is most frequent in 25-34 year olds $(30 \%)$, whereas in women smoking is most frequent among 15-24 year olds (21\%) and declines with age. Three per cent of Finnish women and men report that they have stopped smoking one to 12 months ago and $16 \%$ of women and $19 \%$ of men report that they have stopped smoking more than a year ago. ${ }^{32}$

A reformed Tobacco Control Act (enforced in 1995) prohibited smoking in all joint and public premises of workplaces in Finland. The employer has two options to implement the act: impose a total ban of smoking or permit smoking in designated smoking rooms or areas with separate ventilation systems and lower air pressure than non-smoking spaces. ${ }^{33}$ Of Finnish employees, $36 \%$ report that no one is smoking at their workplace, 54\% report that smoking is permitted in a separate room at their workplace, $5 \%$ report that it is permitted also in private rooms, and $6 \%$ that it is permitted also elsewhere. ${ }^{32}$

\section{METHODS}

\section{Study population}

Data were drawn from the combined sample of two ongoing Finnish cohort studies, the 10-town study and the hospital personnel study. ${ }^{34-35}$ These studies are planned and carried 
out together to explore the relations between behavioural and psychosocial factors and health. The studies are focused on the entire staff in 10 towns and 21 central and regional hospitals. The sample covers almost $20 \%$ of the full time employees working in the Finnish municipal sector. In 20002002, 48592 full time employees (32 293 from the towns and 16299 from the hospitals; 39255 women and 9337 men) aged 17-65 years responded to a questionnaire with a response rate of $67 \%$. As $5 \%(n=2402)$ of the respondents did not provide information about their smoking status, the final cohort comprised 46190 employees (37 309 women and 8881 men).

The most common occupations among the respondents in the total sample were registered nurse $(16 \%, n=7741)$, teacher $(10 \%, n=4962)$, practical nurse $(8 \%, n=3985)$, and cleaner $(10 \%, \mathrm{n}=4659)$. The mean age in the sample was 44.6 years (range $17-65, \mathrm{SD}=9.42$ ). Any differences with the eligible population were small. In the 10-town study, figures for participants compared with eligible population ( $\mathrm{n}=47351$ ) were as follows: mean age 44.9 compared with 44.5 years, proportion of women $77 \%$ compared with $72 \%$, proportions of higher grade non-manual, lower grade nonmanual, and manual employees 34\%, 46\%, 20\%, compared with $35 \%, 42 \%$, and $22 \%$, respectively. The corresponding figures for the hospital personnel study $(n=23610)$ were: mean age 43.1 compared with 43.1 years, proportion of women $87 \%$ compared with $84 \%$, proportions of higher grade non-manual, lower grade non-manual, and manual employees $16 \%, 77 \%, 8 \%$ compared with $13 \%, 81 \%$, and $7 \%$ respectively.

The ethics committee of the Finnish Institute of Occupational Health has approved the study.

\section{Work stress}

The measures of the job strain model were derived from the job content questionnaire. ${ }^{36-37}$ The job demands scale deals with workload and work pace (two items; Cronbach's $\alpha=0.71$; range $1-5$; three year test-retest reliability $r=0.55)$ and the job control scale concerns decision authority and skill discretion (eight items; Cronbach's $\alpha=0.82$; range $1-5$; three year test-retest reliability $r=0.70$ ). Job demands and job control responses were summed to define the two work dimensions and the distribution of sum scores were further divided into tertiles to indicate low, intermediate, and high levels on each scale. To create the job strain indicator, we dichotomised the job demand and job control scales at their median points and formed the following four categories: low job strain (low demands combined with high control), active jobs (high demands combined with high control), passive jobs (low demands combined with low control), and high strain (high demands combined with low control). ${ }^{13-14}$

Effort in work was measured with the question "How much do you feel you invest in your job in terms of skill and energy?" ( 1 = "very little", $5=$ "very much"). Rewards were measured by the following three items (Cronbach's $\alpha=0.64$ ): "How much do you feel you get in return from your work in terms of income, job benefits, etc.?", "How much do you feel you get in return from your work in terms of recognition and prestige?", and "How much do you feel you get in return from your work in terms of personal satisfaction?" ( 1 = "very little", $5=$ "very much"). ${ }^{38}$ We created the indicator of effort-reward imbalance by calculating the ratio between the response score in the effort scale and the sum response score in the rewards scale. The resulting quotient was divided into thirds to indicate low, intermediate, and high effort-reward imbalance. ${ }^{2}$ Because part of the hospital sample did not contain the effort-reward imbalance measure, the analyses including effort-reward variable involved 38602 participants.

With regard to the scales calculated for total job demands, total job control, and total rewards, if half or more of the component items were missing, a value of missing was recorded in the total.

Table 1 Characteristics of the study sample (\%)

\begin{tabular}{|c|c|c|c|c|c|}
\hline & \multirow[b]{2}{*}{$\begin{array}{l}\text { Number of } \\
\text { participants } \\
(\%)\end{array}$} & \multicolumn{4}{|c|}{ Smoking status and intensity (cigarettes per day) } \\
\hline & & $\begin{array}{l}\text { Non- } \\
\text { smokers } \\
\text { ( } n=37961 \text { ) }\end{array}$ & $\begin{array}{l}\text { Light smokers } \\
\text { (1-9 cigarettes) } \\
(\mathrm{n}=3395)\end{array}$ & $\begin{array}{l}\text { Medium smokers } \\
(10-19 \text { cigarettes }) \\
(n=3615)\end{array}$ & $\begin{array}{l}\text { Heavy smokers } \\
(\geqslant 20 \text { cigareftes) } \\
(n=1120)\end{array}$ \\
\hline All & 46190 & 82.4 & 7.4 & 7.8 & 2.4 \\
\hline \multicolumn{6}{|l|}{ Sex } \\
\hline Women & $37309(81)$ & 83.7 & 7.7 & 7.2 & 1.4 \\
\hline Men & 8881 (19) & 76.8 & 5.9 & 10.3 & 6.9 \\
\hline \multicolumn{6}{|l|}{ Age group $(y)$} \\
\hline $17-29$ & $3542(8)$ & 79.1 & 10.9 & 8.8 & 1.2 \\
\hline $30-39$ & $10179(22)$ & 80.8 & 8.7 & 8.5 & 2.0 \\
\hline $40-49$ & $15891(34)$ & 80.3 & 8.1 & 8.8 & 2.8 \\
\hline $50-59$ & $15312(33)$ & 85.6 & 5.3 & 6.5 & 2.6 \\
\hline $60-65$ & $1240(3)$ & 90.8 & 3.7 & 3.7 & 1.8 \\
\hline \multicolumn{6}{|l|}{ Basic education } \\
\hline Common school & $10034(22)$ & 79.1 & 6.6 & 10.3 & 4.0 \\
\hline Comprehensive/ & $13153(29)$ & 76.1 & 9.3 & 11.4 & 3.2 \\
\hline High school & $22181(49)$ & 87.5 & 6.5 & 4.6 & 1.3 \\
\hline \multicolumn{6}{|l|}{ Marital status } \\
\hline Married/living with & $34735(76)$ & 84.4 & 6.9 & 6.8 & 1.9 \\
\hline $\begin{array}{l}\text { a partner } \\
\text { Other }\end{array}$ & $11008(24)$ & 76.1 & 8.9 & 11.0 & 4.0 \\
\hline \multicolumn{6}{|l|}{ Occupational status } \\
\hline Manual & $6863(15)$ & 72.8 & 7.7 & 13.2 & 6.3 \\
\hline $\begin{array}{l}\text { Lower grade } \\
\text { non-manual }\end{array}$ & $25709(58)$ & 82.4 & 8.0 & 7.9 & 1.7 \\
\hline $\begin{array}{l}\text { Higher grade } \\
\text { non-manual }\end{array}$ & $12259(27)$ & 88.1 & 5.9 & 4.5 & 1.5 \\
\hline \multicolumn{6}{|l|}{ Type of employment } \\
\hline Permanent & $36710(82)$ & 82.6 & 6.9 & 7.9 & 2.6 \\
\hline Temporary & $8251(18)$ & 81.3 & 9.5 & 7.8 & 1.5 \\
\hline
\end{tabular}


Table 2 Relation of smoking status with job strain and effort-reward imbalance: adjusted odds ratios (ORs) and their 95\% confidence intervals (Cls)

\begin{tabular}{|c|c|c|c|c|c|c|c|}
\hline & \multicolumn{3}{|l|}{ Women } & \multicolumn{3}{|l|}{ Men } & \multirow{2}{*}{$\begin{array}{l}p \text { for sex } \\
\text { interaction }\end{array}$} \\
\hline & Number & $\mathrm{OR}^{*}$ & $(95 \% \mathrm{Cl})$ & Number & $\mathrm{OR}^{*}$ & $(95 \% \mathrm{Cl})$ & \\
\hline Job control (component of job strain) & & & & & & & 0.776 \\
\hline High job control & 11033 & 1.00 & & 2739 & 1.00 & & \\
\hline Intermediate job control & 12428 & 0.94 & (0.87 to 1.01$)$ & 2925 & 0.98 & (0.86 to 1.11$)$ & \\
\hline Low job control & 11454 & 0.96 & (0.89 to 1.04$)$ & 2490 & 1.01 & $(0.88$ to 1.17$)$ & \\
\hline Job demands (component of job strain) & & & & & & & 0.616 \\
\hline Low job demands & 8547 & 1.00 & & 2403 & 1.00 & & \\
\hline Intermediate job demands & 13825 & 0.92 & (0.85 to 0.99 ) & 3431 & 0.97 & $(0.86$ to 1.10$)$ & \\
\hline High job demands & 12452 & 1.01 & $(0.94$ to 1.09$)$ & 2310 & 0.99 & $(0.87$ to 1.14$)$ & \\
\hline Job strain & & & & & & & \\
\hline Low strain & 8316 & 1.00 & & 2173 & 1.00 & & 0.083 \\
\hline Active jobs & 10284 & 1.00 & $(0.92$ to 1.09$)$ & 2398 & 0.87 & $(0.76$ to 1.01$)$ & \\
\hline Passive jobs & 7387 & 1.02 & $(0.93$ to 1.11$)$ & 2021 & 0.88 & $(0.75$ to 1.02$)$ & \\
\hline High strain & 8792 & 1.04 & $(0.96$ to 1.13$)$ & 1548 & 1.00 & $(0.86$ to 1.17$)$ & \\
\hline Effort (component of effort-reward imbalance & & & & & & & 0.019 \\
\hline High effort & 12908 & 1.00 & & 2169 & 1.00 & & \\
\hline Intermediate effort & 18037 & 0.88 & (0.83 to 0.94 ) & 4363 & 1.09 & (0.96 to 1.24 ) & \\
\hline Low effort & 3860 & 0.83 & $(0.75$ to 0.92$)$ & 1605 & 0.95 & $(0.81$ to 1.11$)$ & \\
\hline Rewards (component of effort-reward & & & & & & & 0.292 \\
\hline $\begin{array}{l}\text { Imbalance) } \\
\text { High rewards }\end{array}$ & 10236 & 1.00 & & 2405 & 1.00 & & \\
\hline Intermediate rewards & 10379 & 1.03 & (0.96 to 1.11$)$ & 2355 & 1.05 & (0.91 to 1.21$)$ & \\
\hline Low rewards & 8534 & 1.20 & $(1.11$ to 1.30$)$ & 2501 & 1.15 & (1.00 to 1.33 ) & \\
\hline Effort-reward imbalance & & & & & & & 0.129 \\
\hline Low imbalance & 9044 & 1.00 & & 2652 & 1.00 & & \\
\hline Intermediate imbalance & 11156 & 1.13 & (1.05 to 1.22 ) & 2441 & 1.01 & (0.88 to 1.15 ) & \\
\hline High imbalance & 8831 & 1.28 & (1.19 to 1.39 ) & 2152 & 1.13 & $(0.98$ to 1.29$)$ & \\
\hline
\end{tabular}

Job strain and effort-reward imbalance measures were intercorrelated $(r=0.265, \mathrm{p}<0.001$, two tailed test).

\section{Smoking}

Smoking was measured in standard ways using the following questions: "Do you smoke or have you previously smoked regularly, that is, daily or nearly daily?", "If you have smoked, do you still smoke regularly?", and "How many cigarettes you smoke (or smoked) a day on average?" From this information, we derived smoking status (non-smoker versus smoker) and, for smokers, smoking intensity (the number of cigarettes smoked per day). The intensity categories were: $1=$ light smoker ( $1-9$ cigarettes $), 2=$ medium smoker (10-19 cigarettes), and $3=$ heavy smoker ( 20 or more cigarettes). ${ }^{26}$

\section{Other variables}

The following background factors were measured: sex, age, basic education (common school, comprehensive or middle school, high school), occupational status (higher grade nonmanual, lower grade non-manual, manual; based on the Statistics Finland classification of the five digit occupational titles), type of employment (permanent compared with temporary), marital status (married/living with a partner compared with other). Sex, age, occupational status, and type of employment were obtained from the employers' registers.

\section{Statistical analyses}

Binary logistic regression models were used to calculate adjusted odds ratios (ORs) and their 95\% confidence intervals (CIs) for smoking status and for ex-smoking according to work stress indicators. The relation between work stress indicators and smoking intensity was studied using multinomial logistic regression models. ${ }^{39}$ The hypothetically least stressful work condition was selected as the reference category in each indicator of work stress in all analyses.

All analyses were adjusted for potential confounders: age, basic education, occupational status, type of employment, and marital status. To evaluate independent effects, job strain and effort-reward imbalance were additionally controlled for each other. Furthermore, we tested whether associations between work stress indicators and smoking were independent of sex and occupational status (SES) by applying cross product terms sex $\times$ work stress measures and SES $\times$ work stress measures in the models analysing the relation of work stress with smoking status and ex-smoking.

The analyses were conducted separately for women and men and were performed by using the SPSS 11.5 (SPSS, Chicago, IL) and SAS 8.2 (SAS Institute, Cary, NC) software packages.

Because of missing values, the number of subjects varies between tables and between the examined variables.

\section{RESULTS}

Table 1 gives the characteristics of the study sample. Seventeen per cent of women and $24 \%$ of men reported that they currently smoke daily or nearly daily. Fifteen per cent of women and $22 \%$ of men were ex-smokers. Of smokers, $42 \%$ smoked 1-9 cigarettes a day, 44\% 10-19 cigarettes a day, and $14 \% 20$ or more cigarettes a day. Men smoked more intensively: $30 \%$ of male smokers compared with $8 \%$ of female smokers smoked 20 or more cigarettes a day $(\mathrm{p}<0.001)$.

\section{Work stress and smoking status}

Table 2 shows the results from binary logistic regression analyses on the associations between the two work stress models and smoking. Effort-reward imbalance was associated with prevalent smoking. Odds of being a smoker were 1.28-fold higher among women and 1.13-fold higher among men with high effort-reward imbalance compared with female and male employees with low effort-reward imbalance, respectively. Of the components of the effort-reward imbalance model, low rewards were associated with an increased likelihood of being a smoker. Moreover, lower effort was associated with a decreased likelihood of smoking in women. Neither job strain nor any of its components was significantly associated with smoking status. 
Table 3 Relation of smoking intensity with job strain and effort-reward imbalance among smokers: adjusted odds ratios (ORs) and their $95 \%$ confidence intervals (Cls)

\begin{tabular}{|c|c|c|c|c|c|c|c|c|c|}
\hline & \multicolumn{4}{|c|}{ Women } & \multicolumn{4}{|l|}{ Men } & \multirow{3}{*}{$\begin{array}{l}\text { p for sex } \\
\text { interaction }\end{array}$} \\
\hline & \multicolumn{2}{|c|}{ 10-19 cigareftes } & \multicolumn{2}{|c|}{$20+$ cigarettes } & \multicolumn{2}{|c|}{ 10-19 cigarettes } & \multicolumn{2}{|c|}{$20+$ cigareftes } & \\
\hline & $\mathrm{OR}^{*}$ & $(95 \% \mathrm{Cl})$ & $\mathrm{OR}^{*}$ & $(95 \% \mathrm{Cl})$ & $\overline{\mathrm{OR}^{*}}$ & $(95 \% \mathrm{Cl})$ & $\overline{\mathrm{OR}^{*}}$ & $(95 \% \mathrm{Cl})$ & \\
\hline $\begin{array}{l}\text { Job control (component of job } \\
\text { strain) }\end{array}$ & & & & & & & & & 0.356 \\
\hline High job control & 1.00 & & 1.00 & & 1.00 & & 1.00 & & \\
\hline Intermediate job control & 1.05 & (0.91 to 1.21$)$ & 1.13 & (0.87 to 1.48$)$ & 1.20 & $(0.91$ to 1.59$)$ & 1.22 & $(0.88$ to 1.70$)$ & \\
\hline Low job control & 1.19 & (1.03 to 1.38 ) & 1.49 & (1.15 to 1.94 ) & 1.28 & $(0.93$ to 1.75$)$ & 1.42 & (0.99 to 2.03 ) & \\
\hline $\begin{array}{l}\text { Job demands (component of job } \\
\text { strain) }\end{array}$ & & & & & & & & & 0.841 \\
\hline Low job demands & 1.00 & & 1.00 & & 1.00 & & 1.00 & & \\
\hline Intermediate job demands & 0.99 & (0.99 to 1.14$)$ & 1.14 & (0.89 to 1.48$)$ & 0.92 & $(0.70$ to 1.21$)$ & 1.04 & $(0.76$ to 1.42$)$ & \\
\hline High job demands & 0.97 & (0.86 to 1.11$)$ & 1.07 & (0.83 to 1.39 ) & 0.90 & $(0.67$ to 1.22$)$ & 0.92 & $(0.65$ to 1.30$)$ & \\
\hline Job strain & & & & & & & & & 0.114 \\
\hline Low strain & 1.00 & & 1.00 & & 1.00 & & 1.00 & & \\
\hline Active jobs & 1.01 & $(0.86$ to 1.19$)$ & 1.37 & (1.01 to 1.87$)$ & 1.06 & $(0.78$ to 1.45$)$ & 0.91 & (0.63 to 1.32$)$ & \\
\hline Passive jobs & 1.15 & $(0.97$ to 1.35$)$ & 1.61 & $(1.18$ to 2.20$)$ & 1.23 & (0.88 to 1.72$)$ & 1.38 & $(0.95$ to 2.01$)$ & \\
\hline High strain & 1.16 & (0.99 to 1.36 ) & 1.55 & (1.14 to 2.10 ) & 1.11 & $(0.78$ to 1.58$)$ & 1.19 & (0.80 to 1.77 ) & \\
\hline $\begin{array}{l}\text { Effort (component of effort-reward } \\
\text { imbalance) }\end{array}$ & & & & & & & & & 0.633 \\
\hline High effort & 1.00 & & 1.00 & & 1.00 & & 1.00 & & \\
\hline Intermediate effort & 1.01 & (0.90 to 1.14$)$ & 1.03 & (0.83 to 1.28$)$ & 0.88 & $(0.67$ to 1.17$)$ & 0.96 & $(0.69$ to 1.33$)$ & \\
\hline Low effort & 1.31 & (1.08 to 1.59$)$ & 1.66 & (1.21 to 2.27 ) & 0.88 & $(0.61$ to 1.27$)$ & 1.12 & $(0.74$ to 1.68$)$ & \\
\hline $\begin{array}{l}\text { Rewards (component of effort- } \\
\text { reward imbalance) }\end{array}$ & & & & & & & & & 0.711 \\
\hline High rewards & 1.00 & & 1.00 & & 1.00 & & 1.00 & & \\
\hline Intermediate rewards & 1.24 & (1.07 to 1.44$)$ & 1.20 & (0.92 to 1.57 ) & 1.09 & $(0.80$ to 1.49$)$ & 1.11 & (0.77 to 1.59 ) & \\
\hline Low rewards & 1.26 & $(1.08$ to 1.46$)$ & 1.58 & (1.22 to 2.04 ) & 1.26 & $(0.92$ to 1.73$)$ & 1.61 & $(1.13$ to 2.30$)$ & \\
\hline Effort-reward imbalance & & & & & & & & & 0.521 \\
\hline Low imbalance & 1.00 & & 1.00 & & 1.00 & & 1.00 & & \\
\hline Intermediate imbalance & 1.15 & (1.00 to 1.34$)$ & 1.03 & (0.79 to 1.34 ) & 1.01 & $(0.75$ to 1.35$)$ & 0.75 & $(0.53$ to 1.05$)$ & \\
\hline High imbalance & 1.19 & (1.03 to 1.39 ) & 1.28 & (0.98 to 1.66$)$ & 1.20 & $(0.88$ to 1.63$)$ & 1.23 & $(0.88$ to 1.73$)$ & \\
\hline
\end{tabular}

Light smokers (1-9 cigarettes per day) formed the reference category within the smoking intensity indicator. *Adjusted for age, basic education, occupational status, type of employment, and marital status.

Table 4 Relation of ex-smoking with job strain and effort-reward imbalance among former and current smokers: adjusted odds ratios (ORs) and their $95 \%$ confidence intervals (Cls)

\begin{tabular}{|c|c|c|c|c|c|c|c|}
\hline & \multicolumn{3}{|l|}{ Women } & \multicolumn{3}{|l|}{ Men } & \multirow[b]{2}{*}{$p$ for sex interaction } \\
\hline & Number & $\mathrm{OR}^{*}$ & $(95 \% \mathrm{Cl})$ & Number & $\mathrm{OR}^{*}$ & $(95 \% \mathrm{Cl})$ & \\
\hline Job control (component of job strain) & & & & & & & 0.594 \\
\hline High job control & 3429 & 1.00 & & 1199 & 1.00 & & \\
\hline Intermediate job control & 3975 & 1.01 & $(0.92$ to 1.11$)$ & 1310 & 0.90 & (0.77 to 1.07 ) & \\
\hline Low job control & 4004 & 0.98 & (0.89 to 1.08$)$ & 1245 & 0.87 & $(0.73$ to 1.04$)$ & \\
\hline Job demands (component of job strain) & & & & & & & 0.760 \\
\hline Low job demands & 2978 & 1.00 & & 1186 & 1.00 & & \\
\hline Intermediate job demands & 4387 & 0.99 & (0.90 to 1.09$)$ & 1582 & 0.97 & (0.83 to 1.13 ) & \\
\hline High job demands & 4010 & 0.90 & $(0.82$ to 0.99$)$ & 983 & 0.85 & $(0.71$ to 1.01$)$ & \\
\hline \multicolumn{8}{|l|}{ Job strain } \\
\hline Low strain & 2635 & 1.00 & & 1024 & 1.00 & & 0.206 \\
\hline Active jobs & 3127 & 0.96 & (0.86 to 1.07$)$ & 976 & 0.98 & (0.82 to 1.18$)$ & \\
\hline Passive jobs & 2607 & 0.95 & (0.85 to 1.06$)$ & 1012 & 1.07 & $(0.88$ to 1.28$)$ & \\
\hline High strain & 2994 & 0.88 & $(0.79$ to 0.99$)$ & 737 & 0.83 & $(0.68$ to 1.01$)$ & \\
\hline \multicolumn{8}{|l|}{$\begin{array}{l}\text { Effort (component of effort-reward } \\
\text { imbalance) }\end{array}$} \\
\hline High effort & 4132 & 1.00 & & 915 & 1.00 & & 0.315 \\
\hline Intermediate effort & 5918 & 1.18 & (1.08 to 1.28 ) & 2069 & 1.03 & (0.88 to 1.21$)$ & \\
\hline Low effort & 1326 & 1.27 & (1.12 to 1.44 ) & 772 & 1.15 & $(0.93$ to 1.41$)$ & \\
\hline \multicolumn{8}{|l|}{$\begin{array}{l}\text { Rewards (component of effort-reward } \\
\text { imbalance) }\end{array}$} \\
\hline High rewards & 3102 & 1.00 & & 1038 & 1.00 & & 0.729 \\
\hline Intermediate rewards & 3388 & 1.03 & (0.93 to 1.14 ) & 1078 & 0.95 & (0.79 to 1.13 ) & \\
\hline Low rewards & 3117 & 0.93 & (0.84 to 1.04 ) & 1265 & 0.88 & $(0.74$ to 1.06$)$ & \\
\hline \multicolumn{8}{|l|}{ Effort-reward imbalance } \\
\hline Low imbalance & 2791 & 1.00 & & 1200 & 1.00 & & 0.590 \\
\hline Intermediate imbalance & 3587 & 0.92 & (0.83 to 1.02$)$ & 1096 & 0.96 & (0.81 to 1.14 ) & \\
\hline High imbalance & 3194 & 0.88 & $(0.79$ to 0.98$)$ & 1080 & 0.93 & $(0.78$ to 1.10$)$ & \\
\hline
\end{tabular}


Simultaneous adjustment for job strain and effort-reward imbalance did not attenuate the odds ratios of smoking among employees with high effort-reward imbalance: ORs were $1.29(95 \% \mathrm{CI}=1.19$ to 1.40$)$ for women and $1.13(95 \%$ $\mathrm{CI}=0.98$ to 1.30 ) for men. Besides, active jobs were associated with a decreased likelihood of smoking in men ( $\mathrm{OR}=0.85,95 \% \mathrm{CI}=0.73$ to 1.00 ) (data not shown).

The interaction between sex and effort was significant $(p=0.019)$, whereas other interactions between sex and job strain and effort-reward imbalance measures were not (see table 2). In addition, the interactions between occupational status and job control, job strain, effort, and effort-reward imbalance were significant (all $\mathrm{p}$ values $<0.01$ ). Further analysis showed that between occupational status groups, the main differences were between higher grade non-manual employees and others. High effort-reward imbalance and lower rewards were associated with an increased likelihood of smoking only among lower grade non-manual and manual employees. Low control and low effort were related to a higher likelihood of smoking among higher grade nonmanual employees. In contrast, low job control among lower grade non-manual employees, and low effort among manual and lower grade non-manual employees were associated with a decreased likelihood of smoking.

\section{Work stress and smoking intensity}

Table 3 shows adjusted ORs (95\% CI) from multinomial logistic regression models. There was a relation between the two work stress models and intensity of smoking. In women, passive jobs, high job strain, and active jobs were significantly associated with an increased likelihood of smoking 20 or more cigarettes per day and high effort-reward imbalance with an increased likelihood of smoking 10-19 cigarettes per day. Of the components of the work stress models, low job control, low effort, and low rewards were associated with a higher likelihood of more intensive smoking among women. In men, low rewards were significantly associated with an increased likelihood of smoking 20 or more cigarettes per day. In addition, low control, passive jobs, high job strain, low effort, and high effort-reward imbalance showed similar associations with smoking intensity than those in women but probably because of a smaller sample size they did not reach statistical significance.

When job strain and effort-reward imbalance were concurrently adjusted for, the significant association between high effort-reward imbalance and smoking 10-19 cigarettes per day persisted $(\mathrm{OR}=1.19,95 \% \mathrm{CI}=1.01$ to 1.39$)$ among women. Moreover, the associations between high job strain and an increased likelihood of smoking 20 or more cigarettes per day $(\mathrm{OR}=1.42,95 \% \mathrm{CI}=1.02$ to 1.96$)$ and between passive jobs and an increased likelihood of smoking 20 or more cigarettes per day $(\mathrm{OR}=1.52,95 \% \mathrm{CI}=1.10$ to 2.10 ) remained significant (data not shown).

None of the interaction terms between sex and work stress variables were significant (see table 3 ).

\section{Work stress and ex-smoking}

Table 4 depicts the results from binary logistic regression analyses on the associations between the two work stress models and ex-smoking among former and current smokers. Among women, high job demands, high job strain, and high effort-reward imbalance were significantly associated with an increased likelihood of being a current smoker whereas lower effort was associated with an increased likelihood of being an ex-smoker. In men, these work stress measures showed similar associations with ex-smoking than those in women but again probably because of a smaller sample size they did not reach statistical significance.

\section{Key points}

- Employees with high stress were more likely to be smokers than their colleagues with low stress; independent of age, basic education, occupational status, type of employment, and marital status.

- Higher work stress was associated with greater smoking intensity among smokers.

- Among former and current smokers, higher work stress was associated with an increased likelihood of being a current smoker.

- Both stress models provide supplementary information on important stressors in the psychosocial work environment.

After simultaneous adjustment for job strain and effortreward imbalance, the relation between high job strain and a lower likelihood of ex-smoking among women remained significant $(\mathrm{OR}=0.87,95 \% \mathrm{CI}=0.77$ to 0.99 ) (data not shown).

The interactions between sex and work stress measures were not statistically significant (see table 4), but the interactions between occupational status and job control, job strain, and effort were significant (all p values $<0.01$ ). Between occupational status groups, again, the main differences were between higher grade non-manual employees and others. Low control was associated with an increased likelihood of current smoking among higher grade nonmanual employees. Low effort was associated with a higher and high effort-reward imbalance with a lower likelihood of ex-smoking among lower grade non-manual and manual employees. High job demands and high job strain were additionally related to an increased likelihood of current smoking among manual workers (data not shown).

\section{DISCUSSION}

Our findings on 46190 employees showed that work stress defined as job strain and effort-reward imbalance was associated with smoking. After the effects of age, basic education, occupational status, type of employment, and marital status were accounted for, employees with high stress were found more often to be smokers than their colleagues with low stress. Among smokers higher work stress was associated with greater smoking intensity. Furthermore, in current and ex-smokers, higher stress was associated with a higher likelihood of being a current smoker. The independent associations between both work stress models and smoking indicate that both stress models provide supplementary information on important stressors in the psychosocial work environment.

The magnitude of the relations between work stress variables and smoking status were not great. This may be because smoking is usually started before entering into full time work and maintained by other cultural and social factors. ${ }^{15}$ Nevertheless, smoking intensity can vary during adulthood and smoking can be stopped at any point of life. Based on our findings, it seems probable that workplace stress influences in particular the number of cigarettes smoked and the maintenance of the smoking habit rather than the smoking status in itself. ${ }^{24}$ In accordance with this hypothesis, there is more evidence for an association between job strain and smoking intensity than for job strain and smoking status. ${ }^{28}$

In general, our findings are consistent with studies suggesting an association of job strain ${ }^{25}$ and effort-reward 


\section{Policy implications}

Reducing work stress by increasing job control, decreasing job strain, and by finding a better balance between personal efforts and rewards gained from work might help the smoking cessation efforts.

imbalance ${ }^{31}$ with smoking, although these previous studies are on male populations. However, other studies have reported no association between job strain and smoking. ${ }^{15} 182628-29$ Potential reasons for these inconsistencies include small sample sizes in many earlier studies possibly decreasing the likelihood of detecting significant associations; that some of the previous studies did not include smoking intensity; and that many of the studies were limited to male populations only.

As stressful job characteristics are potentially modifiable, it is important to consider practical implications for promoting health among employees. Our findings suggest that reducing stress by increasing job control, decreasing job strain, ${ }^{15-26}$ as well as by finding a better balance between personal efforts and rewards gained from work might help the smoking cessation efforts. Studies of smoking interventions combined with stress management interventions would be a step forward in testing this hypothesis. These studies should also take into account that the aspects of work stress related to smoking seem to vary between occupational status groups.

We recognise the need for caution in interpreting these findings because of some limitations. Firstly, the reliance on cross sectional self reported data in this study may have inflated our results through common method bias. Secondly, self report data on substance use are often subject to underreporting and self reporting may be additionally influenced by recall bias. These may lead to underestimation rather than overestimation of the actual associations. In the future, longitudinal studies using both self reported and objective indicators of work stress would provide an interesting comparison to these findings.

Thirdly, the fact that non-respondents were more often men-that is, those with a higher prevalence and intensity of smoking, may have reduced the likelihood of finding significant associations between work stress indicators and smoking in men.

Fourthly, applications of smoking restrictions may have slightly varied between different workplaces. While some employers may have imposed a total ban of smoking others may have permitted smoking in designated smoking rooms or areas. There is evidence showing an association between workplace smoking restriction policy and employees' smoking behaviour. ${ }^{40}$ Variation in workplace smoking policies may thus have had an effect on the observed relations between work stress measures and smoking.

Finally, although several possible confounding factors were controlled in the analyses, there are other important factors that we were not able to take into account in this study. For example, many work related factors such as smoking behaviour among colleagues can also have an effect on the relation between work stress and smoking.

\section{Conclusions}

These data extend knowledge on the potential indirect pathways through with work stress may affect health. Our findings lend some support to the notion that work stress defined as job strain and effort-reward imbalance, is related to cigarette smoking, the largest preventable risk factor for morbidity and mortality in developed countries. ${ }^{12}$ Moreover, by concurrently controlling for both work stress models, this study found independent relations between both leading work stress models and smoking.

\section{Authors' affiliations}

A Kouvonen, M Kivimäki, Department of Psychology, University of Helsinki, Finland

M Virtanen, Finnish Institute of Occupational Health, Helsinki, Finland J Pentti, J Vahtera, Finnish Institute of Occupational Health, Turku, Finland

Funding: this study was supported by the Finnish Work Environment Fund, the Academy of Finland (projects 77560, 104891, and 105195) and the participating towns and hospitals.

Conflicts of interest: none declared.

Dr Kouvonen was working as a Visiting Fellow Research at the Institute of Work, Health and Organisations, the University of Nottingham when preparing this paper.

\section{REFERENCES}

1 Amick BC III, McDonough P, Chang H, et al. Relationship between all-cause mortality and cumulative working life course psychosocial and physical exposures in the United States labor market from 1968 to 1992. Psychosom Med 2002;64:370-81.

2 Kivimäki $M$, Leino-Arjas $P$, Luukkonen $R$, et al. Work stress and risk of cardiovascular mortality: prospective cohort study of industrial employees. BMJ 2002;325:857-60.

3 Kivimäki M, Vahtera J, Pentti J, et al. Factors underlying the effect of organisational downsizing on health of employees: longitudinal cohort study. BMJ 2000;320:971-5

4 Bosma H, Peter R, Siegrist J, et al. Two alternative job stress models and the risk of coronary heart disease. Am J Public Health 1998;88:68-74.

5 Vahtera J, Kivimäki $M$, Pentti J. Effect of organisational downsizing on health of employees. Lancet 1997;350:1124-8.

6 Lynch J, Krause N, Kaplan GA, et al. Workplace conditions, socioeconomic status, and the risk of mortality and acute myocardial infarction: the Kuopio ischemic heart disease risk factor study. Am J Public Health 1997;87:617-22.

7 Hemingway $\mathrm{H}$, Marmot M. Psychosocial factors in the aetiology and prognosis of coronary heart disease: systematic review of prospective cohort studies. BMJ 1999;318:1460-7.

8 Johnson JV, Stewart W, Hall EM, et al. Long-term psychosocial work environment and cardiovascular mortality among Swedish men. Am J Public Health 1996;86:324-31

9 Theorell T, Karasek RA. Current issues relating to psychosocial job strain and cardiovascular disease research. J Occup Health Psychol 1996;1:9-26.

10 Brunner E, Marmot M. Social organisation, stress, and health. In: Marmot M, Wilkinson RG, eds. Social determinants of health. Oxford: Oxford University Press, 1999:17-43.

11 AHA. AHA guidelines for primary prevention of cardiovascular disease and stroke: 2002 update. Circulation 2002;106:388-91.

12 Bergen AW, Caporaso N. Cigarette smoking. J Natl Cancer Inst 1999;91:1365-75.

13 Karasek R. Job demands, job decision latitude, and mental strain: implications for job redesign. Administrative Science Quarterly 1979;24:285-308.

14 Karasek RA, Theorell T. Healthy work: stress, productivity and the reconstruction of working life. New York: Basic Books, 1990.

15 Landsbergis PA, Schnall PL, Deitz DK, ef al. Job strain and health behaviors: results of a prospective study. Am J Health Promot 1998;12:237-45.

16 Kawakami N, Haratani T, Araki S. Job strain and arterial blood pressure, serum cholesterol, and smoking as risk factors for coronary heart disease in Japan. Int Arch Occup Environ Health 1998;71:429-32.

17 Alterman T, Shekelle RB, Vernon SW, et al. Decision latitude, psychologic demand, job strain, and coronary heart disease in the Western Electric study. Am J Epidemiol 1994; 139:620-7.

18 Reed DW, LaCroix AZ, Karasek RA, et al. Occupational strain and the incidence of coronary heart disease. Am J Epidemiol 1989;129:495-502.

19 Pieper C, LaCroix AZ, Karasek RA. The relation of psychosocial dimensions of work with coronary heart disease risk factors: a meta-analysis of five United States data bases. Am J Epidemiol 1989;129:483-94.

20 Tsutsumi A, Kayaba K, Yoshimura M, et al. Association between job characteristics and health behaviors in Japanese rural workers. Int J Behav Med 2003;10:125-42.

21 Jönsson D, Rosengren A, Dotevall A, et al. Job control, demands and social support at work in relation to cardiovascular risk factors in MONICA 1995, Goteborg. J Cardiovasc Risk 1999;6:379-85.

22 Niedhammer I, Goldberg M, Leclerc A, et al. Psychosocial work environment and cardiovascular risk factors in an occupational cohort in France. $J$ Epidemiol Community Health 1998;52:93-100.

23 Hellerstedt WL, Jeffery RW. The association of job strain and health behaviours in men and women. Int J Epidemiol 1997;26:575-83.

24 Johansson G, Johnson JV, Hall EM. Smoking and sedentary behaviour as related to work organization. Soc Sci Med 1991;32:837-46.

25 Green KL, Johnson JV. The effects of psychosocial work organization on patterns of cigarette smoking among male chemical plant employees. Am J Public Health 1990;80:1368-71. 
26 Otten F, Bosma H, Swinkels $\mathrm{H}$. Job stress and smoking in the Dutch labour force. Eur J Public Health 1999;9:58-61.

27 Brisson C, Larocque B, Moisan J, et al. Psychosocial factors at work, smoking, sedentary behavior, and body mass index: a prevalence study among 6995 white collar workers. J Occup Environ Med 2000;42:40-6.

28 Loon van AJM, Tijhuis M, Surtees PG, et al. Lifestyle risk factors for cancer: the relationship with psychosocial work environment. Int J Epidemiol 2000;29:785-92

29 Netterstrom B, Kristensen TS, Damsgaard MT, et al. Job strain and cardiovascular risk factors: a cross sectional study of employed Danish men and women. $\mathrm{Br} J$ Ind Med 1991;48:684-9.

30 Siegrist J. Adverse health effects of high-effort/low-reward conditions. J Occup Health Psychol 1996;1:27-41.

31 Peter R. Job stressors, coping characteristics, and the development of coronary heart disease (CHD): results from two studies. PsychologischeBeitrage 1995;37:40-5.

32 Helakorpi S, Patja K, Prättälä R, et al. Health behaviour and health among Finnish adult population, spring 2003. Helsinki: Publications of the National Public Health Institute B17, 2003:191.
33 Heloma A, Jaakkola MS, Kähkönen E, et al. The short-term impact of national smoke-free workplace legislation on passive smoking and tobacco use. Am J Public Health 2001;91:1416-18.

34 Vahtera J, Poikolainen K, Kivimäki $M$, et al. Alcohol intake and sickness absence: a curvilinear relation. Am J Epidemiol 2002:156:969-76.

35 Kivimäki $M$, Virtanen $M$, Vartia $M$, et al. Workplace bullying and the risk of cardiovascular disease and depression. Occup Environ Med 2003;60:779-83.

36 Karasek R. Job content questionnaire and user's guide. Revision 1.1. Los Angeles, CA: Department of Industrial and Systems Engineering, University of Southern Los Angeles, 1985

37 Karasek R, Brisson C, Kawakami N, et al. The job content questionnaire (JCQ): an instrument for internationally comparative assessments of psychological job characteristics. J Occup Health Psychol 1998:3:322-55.

38 Taris TW, Kalimo R, Schaufeli WB. Inequity at work: its measurement and association with worker health. Work Stress 2002;16:287-301.

39 Hosmer DW Jr, Lemeshow S. Applied logistic regression. New York: Wiley, 1989.

40 Fichtenberg CM, Glantz SA. Effect of smoke-free workplaces on smoking behaviour: systematic review. BMJ 2002;325:188-91. 